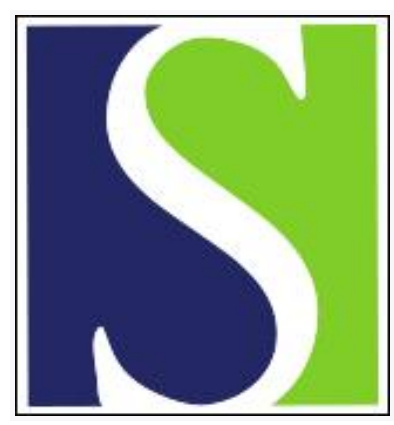

Scand J Work Environ Health 1998;24(3):213-219

https://doi.org/10.5271/sjweh.301

Issue date: Jun 1998

Morbidity among farm workers in a desert country in relation to long-term exposure to pesticides

by Gomes J, Lloyd O, Revitt MD, Basha M

Key terms: aiming test; digit symbol test; erythrocyte acetylcholinesterase; hemoglobin-adjusted erythrocyte cholinesterase; organophosphate

This article in PubMed: www.ncbi.nlm.nih.gov/pubmed/9710374

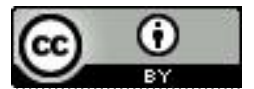




\title{
Morbidity among farm workers in a desert country in relation to long-term exposure to pesticides
}

\author{
by James Gomes, MSc, ${ }^{1}$ Owen Lloyd, PhD, ${ }^{1}$ Mike D Revitt, PhD, ${ }^{2}$ Mansour Basha, MD ${ }^{3}$
}

Gomes J, Lloyd O, Revitt MD, Basha M. Morbidity among farm workers in a desert country in relation to long-term exposure to pesticides. Scand J Work Environ Health 1998;24(3):213-219.

\begin{abstract}
Objectives Farm workers chronically exposed to low levels of pesticides seldom show signs and symptoms of clinical significance. This study investigates subclinical morbidity patterns among male farm workers in a desert country. Methods Migrant-established farm workers $(\mathrm{N}=226)$ were compared with referents $(\mathrm{N}=226)$ and with new farm workers ( $\mathrm{N}=92$ ) who had just entered the country to work on farms. Acetylcholinesterase activity was measured, the aiming test and digit symbol test were applied, and a morbidity profile was collected with a questionnaire.

Results The erythrocyte acetylcholinesterase activity and hemoglobin-adjusted erythrocyte acetylcholinesterase activity were significantly depleted in the established farm workers. The results of the aiming and digit symbol tests were also significantly lower for the established farm workers. For the morbidity profile, irritated conjunctiva $(47.3 \%)$, watery eyes $(52.2 \%)$, blurred vision (63.3\%), dizziness (55.2\%), headache $(63.7 \%)$, muscular pain (61.1\%), and weakness $(76.6 \%)$ were reported by established farm workers in statistically significantly higher numbers than by the referents and new farm workers.

Conclusions Morbidity patterns, such as the health complaints and objective parameters suggested in this study, would be suitable as criteria for identifying farm workers most at risk from pesticide toxicity and as criteria for initiating measures to control and reduce exposure.
\end{abstract}

Key terms aiming test, digit symbol test, erythrocyte acetylcholinesterase, hemoglobin-adjusted erythrocyte cholinesterase, organophosphates.

Crop losses have been effectively controlled through the use of pesticides. However, their use has caused widespread concern over direct exposure during their handling (mixing and spraying) and also during indirect exposure through pesticide residues in food and the general environment (1). Reports of adverse health effects on agricultural workers and the community have generated calls for the most judicious use of pesticides in agriculture and public health $(2,3)$. However, the improper use of pesticides, especially in developing countries, has raised suspicions of increasing morbidity rates for agricultural workers (2). Lack of control and training in the proper use of pesticides on farms has resulted in the exposure of farm workers to toxicologically significant quantities $(1,4)$. Although only a small percentage of those exposed receive doses high enough to cause acute severe effects, the majority are at risk of developing subclinical damage to their health (5).
As reported by pesticide handlers elsewhere, the most common symptoms from chronic low-dose exposure are headache, dizziness, anxiety, vertigo, nausea, and vomiting $(2,3)$. Farm workers subjected to chronic pesticide exposure are also at risk of developing mood disorders, mainly depression, which can be manifested as significantly high suicide rates (4). Cytogenetic effects have also been observed for farm workers chronically exposed to pesticides (5). A 3-fold increase in chromatid breaks has been detected for sprayers at the end of the spraying season in a comparison with unexposed workers (5). Gudumak et al (6) reported that prolonged exposure to pesticides alters the amino acid profile in agricultural pesticide handlers. Significant alterations in amino acids produced clinical manifestations of ill-health in occupationally and chronically exposed agricultural workers (6). Certain cancers, namely, gastric, renal, skin and blood (leukemia and non-Hodgkin lymphoma), have tended to increase $(7,8)$.

1 Department of Community Medicine, Faculty of Medicine \& Health Sciences, UAE University, United Arab Emirates.

Centre for Urban Pollution Research, Middlesex University, London, United Kingdom.

Preventive Medicine Department, Ministry of Health, United Arab Emirates.

Reprint requests to: Mr J Gomes, Department of Community Medicine, Faculty of Medicine \& Health Sciences, PO Box 17666, Al-Ain, United Arab Emirates. [e-mail: jgomes@pcmail.uaeu.ac.ae] 
Decreased conduction velocities have been observed for the motor and sensory fibers by Ruijten et al (9). Autonomic nerve function was also decreased in resting sinus arrhythmia. Acetylcholinesterase activity levels have been reported to be lower in workers exposed to organophosphorus compounds than in unexposed workers (10).

Dose-response relationships to pesticides are difficult to determine among agricultural workers because of the heterogeneity of the pesticides used, the variability of the methods of application, the lack of information on the use of protective measures, and the lack of adequate exposure data (11). Migrant agricultural workers in particular are at increased risk since they do not carry any exposure history with them and most migrant farm workers are unaware that pesticides are toxic and could cause health problems (12). Few comprehensive epidemiologic studies have assessed the magnitude of occupational health problems among farm workers in developing countries, and data on acute and chronic health effects related to their toxic exposures are generally lacking (13-16).

This study aimed at collecting information on some of the key morbidity parameters (both those reported elsewhere and others) among migrant-established farm workers and those working in nonpesticide-related industry. Farm workers who had worked on farms in other countries and who had come to the United Arab Emirates to commence farm work were also studied. Erythrocyte acetylcholinesterase (AChE) activity and neurological and muscular dysfunction were measured in the study population, and the results were correlated with their AChE level and the type of job. The morbidity parameters identified in this study were assessed for their ability to predict the depletion of AChE, the type of job engaged in, and the period of occupational exposure to pesticides.

\section{Subjects and methods}

\section{Subjects}

A population of 544 male expatriate workers recruited from developing countries to work on farms, in industry,

Table 1. Demographic characteristics of the study population.

\begin{tabular}{|c|c|c|c|c|c|c|}
\hline \multirow[t]{2}{*}{ Parameter } & \multicolumn{2}{|c|}{ Referents } & \multicolumn{2}{|c|}{$\begin{array}{c}\text { Farm } \\
\text { workers }\end{array}$} & \multicolumn{2}{|c|}{$\begin{array}{l}\text { New farm } \\
\text { workers }\end{array}$} \\
\hline & Mean & $\mathrm{SD}$ & Mean & SD & Mean & SD \\
\hline $\begin{array}{l}\text { Body mass index }\left(\mathrm{kg} / \mathrm{m}^{2}\right) \\
\text { Systolic blood }\end{array}$ & 23.24 & 3.54 & 21.75 & 3.13 & 20.54 & 3.35 \\
\hline $\begin{array}{l}\text { pressure }(\mathrm{mm} \mathrm{Hg})^{\mathrm{a}} \\
\text { Diastolic blood }\end{array}$ & 118.80 & 15.5 & 120.78 & 17.07 & 115.61 & 10.33 \\
\hline $\begin{array}{l}\text { pressure ( } \mathrm{mm} \mathrm{Hg})^{\mathrm{a}} \\
\text { Heart rate (beats/min) }\end{array}$ & $\begin{array}{l}80.27 \\
70.49\end{array}$ & $\begin{array}{l}12.53 \\
12.79\end{array}$ & $\begin{array}{l}81.66 \\
68.90\end{array}$ & $\begin{array}{l}11.46 \\
11.65\end{array}$ & $\begin{array}{l}77.39 \\
64.67\end{array}$ & $\begin{array}{l}9.20 \\
7.51\end{array}$ \\
\hline
\end{tabular}

a $1 \mathrm{~mm} \mathrm{Hg} \approx 0.133 \mathrm{kPa}$. and as domestic help in the United Arab Emirates took part in this study. The study population was selected from workers attending the occupational health clinic of the Preventive Medicine Department, Ministry of Health; they attended this clinic to obtain a health certificate to renew their residence permit, which would allow them to stay in the country and work in the designated industry. The population consisted of 226 established farm workers, 226 referents matched for age and nationality, and 92 unmatched new farm workers. Both the farm workers and the referents were selected on the basis that they had worked, at least for the past 2 years, in the country in their present jobs. The farm workers lived on the farms and handled tilling, the spraying of pesticides, and the harvesting of farm crops. The selection criteria for the referents were that they had never been occupationally exposed to pesticides or handled pesticides for domestic use; they were employed as domestic workers or in retail shops or in offices or industry. The new farm workers were selected from men who had just come into the country to work on farms and had previously worked for at least 2 years in the farming industry in their home country. The response rate was $99 \%$; 6 people (1 referent, 1 farm worker and 4 new farm workers) did not participate because of a lack of communication skills or because they were afraid to provide a blood sample. The study population, which was mainly ethnic Asians, comprised Pakistanis (30\%), Indians (29\%), Bangladeshis (28\%), Egyptians (9\%) and others (4\%) (Iranians, Jordanians, Sudanese, Syrians and Yemenis). The means of the systolic and diastolic blood pressures of the population were 119.08 (SD 15.54) mm $\mathrm{Hg}$ [15.84 (SD 2.07) $\mathrm{kPa}]$ and 80.36 (SD 11.65) $\mathrm{mm} \mathrm{Hg}$ [10.69 $(\mathrm{SD} 1.55) \mathrm{kPa}$, respectively, and the mean and standard deviation of the hemoglobin level was 13.27 (SD 7.92) g/d1. The body mass index (BMI), systolic and diastolic blood pressures, and heart rate did not differ between the 3 groups (table 1 ).

\section{Questionnaire}

A specifically designed questionnaire was applied to the surveyed population to elicit information on demographic characteristics, health status, work, and dietary habits. Blood pressure was measured using a close-fitting cuff and an aneroid sphygmomanometer. Height and weight were measured, and the BMI was calculated by using the formula BMI $=$ weight $(\mathrm{kg}) /$ height $^{2}(\mathrm{~m})$.

\section{Analyses}

A $10-\mu$ l capillary blood sample was collected to measure AChE and the hemoglobin level $(17,18)$. A Testmate Cholinesterase Kit (19) (EQM Research, Cincinnati, OH, USA) was used to analyze the blood sample for AChE and hemoglobin. In the assessment of neurological dysfunction, memory disorder and loss of neuromuscular coordination status, the digit symbol test and the aiming 
test (20) were applied under controlled and comfortable conditions. The test instructions were given in the relevant native language, and, after a practice session, 1 minute was allowed for the completion of each test. All the subjects were then examined by an occupational physician, who was "blind" to their jobs, to collect information on their past and present health status according to a predesigned checklist.

\section{Morbidity data}

The morbidity pattern was compiled using the 30-day recall information provided by the study population. The checklist for the past health effects included complaints described in previous studies and also other complaints on the basis of protection from presumed toxicologic actions. They included watery eyes, blurred vision, runny nose, itchy skin, dizziness, headache, restlessness, sleeplessness, muscle pain, abdominal pain, weakness, wheeze, and chest tightness. The subjects were also asked to report on any parameter which they experienced while at work or soon after work. The responses to each parameter were classified as experienced "often", "sometimes", or "never". The current health status was assessed from the following observations: conjunctiva (irritated or normal), vision test, wheezy chest, and skin condition of the hands.

\section{Statistical analysis}

The data were analyzed using the statistical package for the social sciences (SPSS) for Windows (21). Student's ttest was used to test the significance of the difference in the categorical variables, and an analysis of variance (ANOVA) was used to test the significance of the difference between the means among the different groups. Multiple regression analysis was used to test the association between AChE depletion and farm work from the results of the aiming and digit symbol tests and the different parameters from the morbidity pattern. The period of exposure of the farm workers was also tested as a dependent variable.

\section{Results}

\section{Measured parameters}

The values for $\mathrm{AChE}$, hemoglobin-adjusted $\mathrm{AChE}$, the aiming test, the digit symbol test, and the period of service for the referents differed highly significantly $(\mathrm{P}<0.0001)$ from the respective values of the established and new farm workers (table 2). But between the 2 groups of farm workers only the difference for $\mathrm{AChE}$ was highly significant, those for the hemoglobin-adjusted AChE value and the aiming test being significant and those for the digit symbol test and the period of service being nonsignificant.

\section{Reported parameters}

Many of the morbidity parameters showed statistically significant differences between the established farm workers, the new farm workers, and the referents. Higher percentages of farm workers than referents reported (often or sometimes) irritated conjunctiva ( $47 \%$ versus $16 \%$ ), watery eyes ( $52 \%$ versus $4 \%$ ), blurred vision ( $63 \%$ versus $7 \%)$, runny nose $(36 \%$ versus $9 \%)$, wheeze $(18 \%$ versus $6 \%$ ), and chest tightness (18\% versus $5 \%$ ) in the past month; these differences were all statistically highly significant (table 3). Greater numbers of farm workers than referents reported dizziness (55\% versus $14 \%$ ), headache $(63 \%$ versus $18 \%)$, restlessness $(41 \%$ versus $0 \%)$, and sleeplessness ( $48 \%$ versus $4 \%$ ); these differences were also highly statistically significant (table 4). Muscular pain, abdominal pain, and weakness were more frequently experienced by the farm workers than by the referents often or sometimes in the past month $(69 \%$ versus $8 \%, 61 \%$ versus $4 \%$, and $77 \%$ versus $10 \%$, respectively); these differences were all highly significant (table 5).

\section{Regression analysis}

The type of job was a highly significant predictor of weakness, abdominal pain, blurred vision, muscular pain, restlessness, and, to a less extent, sleeplessness in the affected population (table 6). Farm work also predicted low

Table 2. Enzyme pattern and neurological function for the referents, established farm workers, and new farm workers. (95\% Cl= $95 \%$ confidence interval, AchE = erythrocyte acetylcholinesterase, HAChE = hemoglobin-adjusted erythrocyte acetylcholinesterase)

\begin{tabular}{|c|c|c|c|c|c|c|c|c|c|}
\hline \multirow[t]{2}{*}{ Parameter } & \multicolumn{2}{|c|}{ Referents } & \multicolumn{2}{|c|}{$\begin{array}{c}\text { Farm } \\
\text { workers }\end{array}$} & \multicolumn{2}{|c|}{$\begin{array}{l}\text { New farm } \\
\text { workers }\end{array}$} & \multicolumn{3}{|c|}{$95 \% \mathrm{Cl}$ for difference } \\
\hline & Mean & $\mathrm{SD}$ & Mean & SD & Mean & SD & $\begin{array}{l}\text { Referents versus } \\
\text { farm workers }\end{array}$ & $\begin{array}{l}\text { Referents versus new } \\
\text { farm workers }\end{array}$ & $\begin{array}{l}\text { Farm workers versus } \\
\text { new farm workers }\end{array}$ \\
\hline $\mathrm{AChE}(\mathrm{Ul} / \mathrm{ml})$ & 4.12 & 0.31 & 3.47 & 0.50 & 4.23 & 0.21 & $0.57-0.73^{*}$ & $-0.18--0.04^{\star}$ & $0.68-0.83^{*}$ \\
\hline HAchE (Ul/g hem) & 31.54 & 2.31 & 28.41 & 6.26 & 33.24 & 1.73 & $2.3-4.01^{*}$ & $-2.22--1.17^{*}$ & $3.93-5.72^{* *}$ \\
\hline Aiming test & 18.98 & 18.55 & 7.17 & 12.05 & 7.99 & 15.24 & $8.92-14.71^{*}$ & $6.7-15.3^{*}$ & $-2.7-4.34^{* *}$ \\
\hline Digit symbol test & 5.97 & 11.70 & 0.90 & 3.83 & 0.74 & 2.89 & $3.45-6.68^{\star}$ & $2.8-7.66^{\star}$ & $-1.04--0.71$ \\
\hline Period of service & 6.31 & 4.54 & 5.04 & 3.62 & 0.06 & 0.46 & $0.52-2.03^{*}$ & $5.31-7.18^{*}$ & $-5.45--4.99$ \\
\hline
\end{tabular}

${ }^{\star} \mathrm{P}$-value $<0.01,{ }^{\star *} \mathrm{P}$-value $<0.001$ 
scores on the aiming and digit symbol tests and low AChE activity levels with a high level of statistical significance. AChE depletion significantly predicted weakness and blurred vision highly significantly and less significantly musclular pain, headache, and chest tightness. Among the 108 farm workers who sometimes experienced blurred vision, 14\% (15 of 108) reported sometimes experiencing double vision, while $40 \%$ (14 of 35 ) reported this symptom as being experienced often. $\mathrm{AChE}$ also predicted a low hemoglobin-adjusted AChE activity in the exposed population significantly and identified the exposed population highly significantly.

\section{Discussion}

Migrant farmers have a low level of literacy and are therefore unable to read the instructions on the labels of pesticide packing (22). These workers, who also disregard

Table 3. Eye problems, respiratory problems, and skin allergy among the referents, established farm workers, and the new farm workers. (NS=not significant)

\begin{tabular}{|c|c|c|c|c|c|c|c|}
\hline \multirow[t]{2}{*}{ Symptom } & \multicolumn{2}{|c|}{ Referents } & \multicolumn{2}{|c|}{ Farm workers } & \multicolumn{3}{|c|}{ New farm workers } \\
\hline & $N$ & $\%$ & $N$ & $\%$ & $N$ & $\%$ & P-value \\
\hline \multicolumn{8}{|l|}{ Conjunctiva } \\
\hline Irritated & 36 & 15.9 & 107 & 47.3 & 16 & 17.4 & \\
\hline Normal & 190 & 84.1 & 119 & 52.7 & 76 & 82.6 & $<0.0001$ \\
\hline \multicolumn{8}{|l|}{ Watery eyes } \\
\hline No & 217 & 96.0 & 108 & 47.8 & 92 & 100 & \\
\hline Sometimes & 9 & 3.9 & 108 & 47.8 & - & 0.0 & \\
\hline Often & - & 0.0 & 10 & 4.4 & - & 0.0 & $<0.0001$ \\
\hline \multicolumn{8}{|l|}{ Blurred vision } \\
\hline No & 210 & 92.9 & 83 & 36.7 & 92 & 100 & \\
\hline Sometimes & 15 & 6.6 & 108 & 47.8 & - & 0.0 & \\
\hline Often & 1 & 0.4 & 35 & 15.5 & - & 0.0 & $<0.0001$ \\
\hline \multicolumn{8}{|l|}{ Runny nose } \\
\hline No & 205 & 90.7 & 143 & 63.3 & 89 & 96.7 & \\
\hline Sometimes & 21 & 9.3 & 78 & 34.5 & 3 & 3.3 & \\
\hline Often & - & 0.0 & 5 & 2.2 & - & 0.0 & $<0.0001$ \\
\hline \multicolumn{8}{|c|}{ Respiratory problems } \\
\hline Normal & 201 & 88.9 & 145 & 64.2 & 92 & 100 & \\
\hline Wheezy & 14 & 6.2 & 41 & 18.1 & - & 0.0 & \\
\hline Tightness & 11 & 4.9 & 40 & 17.7 & - & 0.0 & $<0.0001$ \\
\hline \multicolumn{8}{|l|}{ Skin rash } \\
\hline No & 217 & 96.0 & 209 & 92.5 & 92 & 100 & \\
\hline Yes & 9 & 3.9 & 17 & 7.5 & - & 0.0 & NS \\
\hline
\end{tabular}

${ }^{a}$ Chi-square test between the referents, farm workers, and new farm workers for either the presence or absence of the morbidity parameter.

Table 4. Dizziness, headache, restlessness, and sleep disturbances among referents, established farm workers, and new farm workers.

\begin{tabular}{|c|c|c|c|c|c|c|c|}
\hline \multirow[t]{2}{*}{ Symptom } & \multicolumn{2}{|c|}{ Referents } & \multicolumn{2}{|c|}{ Farm workers } & \multicolumn{3}{|c|}{ New farm workers } \\
\hline & N & $\%$ & $\mathrm{~N}$ & $\%$ & $N$ & $\%$ & P-value ${ }^{a}$ \\
\hline \multicolumn{8}{|l|}{ Dizziness } \\
\hline No & 194 & 85.8 & 101 & 44.7 & 90 & 97.8 & \\
\hline Sometimes & 30 & 13.3 & 107 & 47.3 & 2 & 2.2 & \\
\hline Often & 2 & 0.9 & 8 & 7.9 & - & 0.0 & $<0.0001$ \\
\hline \multicolumn{8}{|l|}{ Headache } \\
\hline No & 186 & 82.3 & 82 & 36.3 & 89 & 96.7 & \\
\hline Sometimes & 33 & 14.6 & 110 & 48.7 & 3 & 3.3 & \\
\hline Often & 7 & 3.1 & 34 & 15.0 & - & 0.0 & $<0.0001$ \\
\hline \multicolumn{8}{|l|}{ Restlessness } \\
\hline No & 226 & 100 & 134 & 59.3 & 92 & 100 & \\
\hline Sometimes & - & 0.0 & 92 & 40.7 & - & 0.0 & $<0.0001$ \\
\hline \multicolumn{8}{|l|}{ Sleeplessness } \\
\hline No & 217 & 96.0 & 118 & 52.2 & 92 & 100 & \\
\hline Sometimes & 9 & 3.9 & 101 & 44.7 & - & 0.0 & \\
\hline Often & - & 0.0 & 7 & 3.1 & - & 0.0 & $<0.0001$ \\
\hline
\end{tabular}

${ }^{\mathrm{a}}$ Chi-square test between the referents, farm workers, and new farm workers for either the presence or absence of the morbidity parameter. 
health and safety measures and treat pesticides and any toxic chemicals as harmless substances, are therefore potential targets for exposure and for subsequent adverse health effects (15). Any subclinical morbidity they experience is usually discounted as general malaise which will pass away the following day. They are also reluctant to seek medical advice because of the fear of losing their jobs (12). Chronic health effects are underreported and usually are not linked in their minds with ill-health from pesticide exposure, even though the exposure is occupational (22). Statistically significant negative relationships have been observed between the use of protective measures and symptoms experienced within hours of exposure after the application of pesticides on a farm (2). Anxiety, nausea, vomiting, weakness, headache, and dizziness have been suggested as potential predictors of pesticide illness $(2,3)$. In our study, we identified a wide range of symptoms and parameters that were experienced often or sometimes by farm workers but not by referents (ie, restlessness, sleeplessness, weakness, headache, muscular pain, abdominal pain, pain in the extremities, allergic reactions including irritated conjunctiva, watery eyes, blurred vision, runny nose, wheeze, and chest tightness). Thelin \& Hoglund (23) reported similar allergic reactions among farm workers who were chronically exposed to pesticides on farms and who were wanting to change jobs. Similar morbidity patterns pertaining to the central nervous system, skin, and eyes were found to be associated with exposure to pesticides by Gupta et al (24). We suggest, therefore, that this list of complaints and measures be used as a checklist for monitoring the health of farm workers exposed to chronic low doses of pesticides and for advising them on the use of protective measures.

Cholinesterase monitoring has been used as a biological marker for the subclinical effects of organophosphate pesticides (25). The depletion of AChE has been reported to follow a dose-response relationship from exposure to organophosphorus pesticides $(10,25)$, and among farm

Table 5. Muscular and abdominal pain and weakness among the referents, established farm workers, and new farm workers.

\begin{tabular}{|c|c|c|c|c|c|c|c|}
\hline \multirow[t]{2}{*}{ Symptom } & \multicolumn{2}{|c|}{ Referents } & \multicolumn{2}{|c|}{ Farm workers } & \multicolumn{3}{|c|}{ New farm workers } \\
\hline & N & $\%$ & N & $\%$ & $\mathrm{~N}$ & $\%$ & P-value ${ }^{a}$ \\
\hline \multicolumn{8}{|l|}{ Muscular pain } \\
\hline $\begin{array}{l}\text { No } \\
\text { Sometimes } \\
\text { Often }\end{array}$ & $\begin{array}{r}207 \\
17 \\
2\end{array}$ & $\begin{array}{r}91.6 \\
7.5 \\
0.9\end{array}$ & $\begin{array}{r}71 \\
127 \\
28\end{array}$ & $\begin{array}{l}31.4 \\
56.2 \\
12.4\end{array}$ & $\begin{array}{r}92 \\
- \\
-\end{array}$ & $\begin{array}{r}100 \\
0.0 \\
0.0\end{array}$ & $<0.0001$ \\
\hline \multicolumn{8}{|l|}{ Abdominal pain } \\
\hline $\begin{array}{l}\text { No } \\
\text { Sometimes } \\
\text { Often }\end{array}$ & $\begin{array}{r}218 \\
8 \\
-\end{array}$ & $\begin{array}{r}96.5 \\
3.5 \\
0.0\end{array}$ & $\begin{array}{r}88 \\
125 \\
13\end{array}$ & $\begin{array}{r}38.9 \\
55.3 \\
5.8\end{array}$ & $\begin{array}{r}92 \\
-\end{array}$ & $\begin{array}{r}100 \\
0.0 \\
0.0\end{array}$ & $<0,0001$ \\
\hline \multicolumn{8}{|l|}{ Weakness } \\
\hline $\begin{array}{l}\text { No } \\
\text { Sometimes } \\
\text { Often }\end{array}$ & $\begin{array}{r}204 \\
20 \\
2\end{array}$ & $\begin{array}{r}90.3 \\
8.8 \\
0.9\end{array}$ & $\begin{array}{r}53 \\
120 \\
53\end{array}$ & $\begin{array}{l}23.5 \\
53.1 \\
23.5\end{array}$ & $\begin{array}{r}89 \\
3 \\
-\end{array}$ & $\begin{array}{r}96.7 \\
3.3 \\
0.0\end{array}$ & $<0.000 t$ \\
\hline
\end{tabular}

" Chi-square test between the referents, farm workers, and new farm workers for either the presence or absence of the morbidity parameter.

Table 6. Prediction of morbidity parameters for the farm workers and the erythrocyte acetylcholinesterase activity (AchE) depletion by multiple regression analysis. (NS $=$ not singificant)

\begin{tabular}{|c|c|c|c|c|c|c|}
\hline \multirow[t]{2}{*}{ Parameters } & \multicolumn{3}{|c|}{ Farm work } & \multicolumn{3}{|c|}{ AChE depletion } \\
\hline & B & $95 \% \mathrm{Cl}$ & P-value & B & $95 \% \mathrm{Cl}$ & P-value \\
\hline Weakness & 0.261 & $0.165-0.359$ & 0.0001 & -0.209 & $-0.179--0.036$ & 0.003 \\
\hline Abdominal pain & 0.315 & $0.190-0.440$ & 0.0001 & 0.005 & $-0.087-0.098$ & NS \\
\hline Blurred vision & 0.182 & $0.077-0.286$ & 0.0001 & -0.098 & $-0.175--0.023$ & 0.01 \\
\hline Muscular pain & 0.170 & $0.055-0.062$ & 0.002 & -0.045 & $-0.124-0.034$ & NS \\
\hline Restlessness & 0.379 & $0.222-0.535$ & 0.0001 & 0.044 & $-0.072-0.159$ & NS \\
\hline Headache & 0.034 & $-0.058-0.128$ & NS & -0.065 & $-0.133-0.001$ & 0.05 \\
\hline Sleeplessness & 0.142 & $0.012-0.273$ & 0.03 & 0.049 & $-0.046-0.143$ & NS \\
\hline Chest tightness & 0.032 & $-0.051-0.114$ & NS & -0.055 & $-0.131-0.065$ & 0.05 \\
\hline Watery eyes & 0.059 & $-0.076-0.194$ & NS & -0.033 & $-0.076-0.079$ & NS \\
\hline Dizzyness & 0.023 & $-0.511--0.28$ & NS & 0.001 & $-0.076-0.079$ & NS \\
\hline Aiming test & -0.012 & $-0.016--0.008$ & 0.0001 & -0.001 & $-0.004--0.001$ & NS \\
\hline Digit symbol test & -0.015 & $-0.023--0.008$ & 0.0001 & -0.002 & $-0.006-0.002$ & NS \\
\hline Hemoglobin-adjusted AchE & -0.008 & $-0.023--0.005$ & NS & 0.034 & $0.027-0.042$ & 0.0001 \\
\hline AChE / farm work & -0.902 & $-1.03--0.772$ & 0.0001 & -0.283 & $-0.0325--0.0243$ & 0.0001 \\
\hline
\end{tabular}


workers the depletion has been related to the intensity of exposure $(25,26)$. Among the adverse health effects from pesticide exposure, dementia has been identified in patients chronically exposed to pesticides, and this finding may suggest a clue to the etiology of some neurodegenerative diseases (27). Postural sway, used in the assessment of neurological dysfunction, has been observed to be significantly affected by exposure to pesticides (28). Memory disorders from chronic exposure to organophosphorus pesticides have been reported (29). The significant depletions of $\mathrm{AChE}$ and hemoglobin-adjusted $\mathrm{AChE}$ in our study were therefore consistent with the finding elsewhere, and it indicated the possibility of subtle diminution of neuromuscular functional integrity.

In our study the positive association of the aiming and digit symbol test results with $\mathrm{AChE}$ activity depletion supported the hypothesis of the presence of subclinical neurological dysfunction and memory disorders among established farm workers and, to a less extent, among new farm workers. These test results therefore showed good agreement with the observations of postural sway and the length of sway used to assess neurological dysfunction in agricultural workers exposed to pesticides (28). Agricultural workers with long exposure to pesticides are therefore potential targets for neurological and memory disorders.

To our knowledge the use of the aiming and digit symbol tests has not been reported in the context of assessing neuromuscular dysfunction among farm workers employed on open farms, although these and other similar tests have been used in assessing health effects from solvent exposure (30). In our study, AChE activity, which has been identified as a good indicator of pesticide exposure (26), also showed positive associations with the results of the aiming and digit symbol tests. Low-level exposure to pesticides induces a state of sensitization (31) among farm workers, who therefore reduce their exposure and, thereby, reduce the possibility of severe intoxication but do not avoid the possibility of mild chronic intoxication. Manifestations of acute clinical toxicity are therefore not commonly seen in farm workers, but subclinical toxicity is prevalent, and it could culminate in a debilitating pesticide-related disease. We therefore suggest that, by monitoring the parameters identified in our study, it may be possible to identify subclinical toxicity at an early stage and thereby prevent the clinical manifestation of a pesticide-related disease at a later date.

\section{Acknowledgments}

The authors acknowledge financial support from the Faculty of Medicine \& Health Sciences, UAE University. We also wish to thank Mr Mustafa Moharram, Jamal
Cheroknath, MY Cheema and SV Anilal for their technical assistance in collecting and handling the data.

\section{References}

1. AI-Saleh IA. Pesticides: a review article. J Environ Pathol Toxicol Oncol 1994;13(3):151-61.

2. Sivayorarathan C, Guanachandran S, Lewis J, Fernando M. Protective measures use and symptoms among agropesticides applicators in Sri Lanka. Social Sci Med $1995 ; 40(4): 431-6$.

3. Lessenger JE, Estock MD, Younglove T. An analysis of 190 cases of suspected pesticide illness. J Am Board Fam Pract $1995 ; 8(4): 278-82$

4. Parron T, Hernandez AF, Villanueva E. Increased risk of suicide with exposure to pesticides in an intensive agricultural area: a 12 year retrospective study. Forensic Sci Int $1996 ; 79(1): 53-63$

5. Mohammed O, Walid AA, Ghada K. Chromosomal aberrations in human lymphocytes from two groups of workers occupationally exposed to pesticides in Syria. Environ Res 1995;70(1):24-9.

6. Gudumak VS, Popovich PI, Nigulianu VI, Marchenko VP, Dontsu ON, Tsaran OA. Diagnostic value of studies of amino acid metabolism during prolonged contact with pesticides. Klinicheskaia Laboratornia Diagnostika 1994;3:1719.

7. Faustini A, Forastieve F, DiBetta L, Magliola EM, Perucci CA. Cohort study of mortality among farmers and agricultural workers. Med Lav 1993;84(1):31 - 41 .

8. Petrelli G, Siepi G, Miligi L, Vineis P. Solvents in pesticides. Scand J Work Environ Health 1993;19(1):63-5.

9. Ruijten MW, Salle HJ, Verberk MM, Surink M. Effect of chronic mixed pesticide exposure on peripheral and autonomic nerve function. Arch Environ Health 1994;49(3):188-95.

10. Karr C, Demen P, Costa LG, Daniell WE, Barnhart S, Miller $M$, et al. Organophosphate pesticide exposure in a group of Washington State orchard applicators. Environ Res 1992;59(1):229-37.

11. Brower DH, Brouwer EJ, van Hemmen JJ. Estimation of long-term exposure to pesticides. Am J Ind Med $1994 ; 25(4): 573-88$.

12. Lantz PM, Dupuis L, Reding D, Krauska M, Lappe K. Peer discussions of cancer among Hispanic migrant farm workers. Public Health Rep 1994;109(4):512-20.

13. Mobed K, Gold EB, Schenker MB. Occupational health problems among migrant and seasonal farm workers. Western J Med 1992;157(3):367-73.

14. Moses M, Johnson ES, Anger WK, Burse VW, Horstman $\mathrm{SW}$, Jackson RJ, et al. Environmental equity and pesticide exposure. Toxicol Ind Health 1993;9(5):913-59.

15. London L, Myers JE. Critical issues for agricultural safety in South Africa. Am J Ind Med 1995;27(1):1-14.

16. London L. Agrichemical hazards in the South African farming sector. South Afr Med J 1992;81(11):560-4.

17. McConnell R, Gordon M, Murray DL, Magnotti R. Hazards of closed pesticide mixing and loading systems - the paradox of protective technology in the third world. Br J Ind Med 1992;49(9):615-9.

18. Meuling WJA, Jongen MJM, van Henmen JJ. An automated 
method for the determination of acetyl and pseudo cholinesterase in hemolyzed whole blood. Am J Ind Med 1992;22:231-41.

19. EQM Research. Practical guide to Testmate. Cincinnati (OH): EQM Research Inc, 1991:1-26.

20. World Health Organization (WHO). Organophosphorus pesticides: an Epidemiological study. Copenhagen: WHO, Regional Office for Europe, 1987:1-138. Environmental health s eries.

21. Norusis MJ. SPSS for Windows release 6.0 Base system: user's guide. Chicago (IL): SPSS Inc, 1993.

22. McDougall L, Magloire L, Hospedales CJ, Tellefson JE, Ooms M, Singh NC, et al. Attitudes and practices of pesticide users in Saint Lucia, West Indies. Bull Pan Am Health Organ 1993;27(1):43-51.

23. Ihelin A, Hoglund S. Change of occupation and retirement among Swedish farmers and farm workers in relation to those in other occupations: a study of "elimination" from farming during the period 1970-1988. Soc Sci Med 1994;38(1):147-51.

24. Gupta BN, Mathur N, Rastogi SK, Srivastava AK, Chandra H, Pangtey BS, et al. Socio-economic, environmental and health aspects of farm workers engaged in mango planta- tions. Biomed Environ Sci 1995;8(4):301—9.

25. Rama DB, Jaga K. Pesticide exposure and cholinesterase levels among farm workers in the Republic of South Africa. Sci Total Environ 1992;122(3):315-9.

26. Gomes J, Lloyd O, Revitt DM, Norman JN. Erythrocyte cholinesterase activity levels in desert farm workers. Occup Med 1997;47:90-4.

27. Cannes A, Costa B, Tacconi P, Pinna L, Fiaschi A. Dementia of Alzheimer type (DAT) in man chronically exposed to pesticides. Acta Neurologica 1992;14(3):220-3.

28. Sacks D, Linz D, Shukla R, Rice C, Bhattacharya A, Suskind $R$. Health status of pesticide applicators: postural stability assessments. J Occup Med 1993;35(12):1196-202.

29. Sereda PI, Gromov LA. Memory disorders in exposure to industrial poisons and pesticides. Krachebnoe Delo 1994;3$4: 56-62$.

30. Foo SC, Lwin S, Chia SE, Jeyaratnam J. Chronic neurobehavioural effects in paint formulators exposed to solvents and noise. Ann Acad Med Singapore 1994;23(5):650-4.

31. Assini R, Fraechiolla F, Ravalli C, Nava C. Allergic diseases caused by pesticides. Med Lav 1994;85(4):321 - 6 .

Received for publication: 30 July 1997 